\title{
Parent-Child Relationships and Bullying
}

\author{
Ebeveyn-Çocuk İlişkisi ve Zorbalık
}

Ayşe Özada ${ }^{1}$, Veli Duyan ${ }^{2}$

\begin{abstract}
Violence in schools is prevalent problem worldwide. Bullying is thought to be the most prevalent form of violence suffered by children. There are different types of bullying as physical, verbal, cyber and indirect. When the long term effects are examined of bullying, negative consequences effect both bullies and victims. Bullies may experience social and psychological problems as well as have the possibility of committing crime and psychiatric disturbances during adulthood. The causes of the bullying vary and are usually not explained for a single reason. Considering the influence of the parents on the child, it turns out that family relationships are an important determinant of being of a bully or victim. In this regard, it is important to ensure the participation of the parents when developing and implementing interventions to prevent and reduce bullying for healthy identity development.
\end{abstract}

Key words: Parent-child relationship, bullying, intervention

\section{ÖZET}

Okullarda yaşanan saldırgan davranışlar tüm dünyada yaygın bir problemdir. Çocukların maruz kaldığı saldırgan davranışların en yaygın şeklinin zorbalık olduğundan bahsedilmektedir. Zorbalı̆̆ın fiziksel, sözel, sanal ve dolaylı pek çok türü bulunmaktadır. Uzun dönemdeki etkileri incelendiğinde zorba eylemler hem uygulayan hem de maruz kalan açısından olumsuz sonuçlara neden olmaktadır. Zorbalık uygulayan öğrenciler sosyal ve ruhsal problemler yaşayabileceği gibi, yetişkinlik döneminde zorba eylemlerde bulunmayan kişilere kıyasla daha yüksek oranda suç işleme ve psikiyatrik rahatsızlık yaşama olasılı̆̆ına sahiptir. Zorbalığın nedenleri çeşitlidir ve genellikle tek bir nedenle açıklanamamaktadır. Ailenin çocuk üzerindeki etkisi düşünüldügünde aile ilişkilerinin zorba davranışlar uygulama ve zorba davranışlara maruz kalmada önemli bir belirleyici olduğu ortaya çıkmaktadır. Bu açıdan, sağlıklı kimlik gelişimi için zorba eylemleri önlemeye ve azaltmaya yönelik müdahaleler geliştirip uygularken ailenin katılımının sağlanması önemli görülmektedir.

Anahtar kelimeler: Ebeveyn-çocuk ilişkisi, zorbalık, müdahale

\author{
Received / Geliş tarihi: 07.07.2017, Accepted / Kabul tarihi: 18.11.2017 \\ ${ }^{1}$ Lefke Avrupa Üniversitesi Sağlık Bilimleri Fakültesi Sosyal Hizmet Bölümü Lefke-KKTC \\ ${ }^{2}$ Ankara Üniversitesi Sağlık Bilimleri Fakültesi Sosyal Hizmet Bölümü, ANKARA \\ *Address for Correspondence / Yazışma Adresi: Veli Duyan, Ankara Üniversitesi Sağlık Bilimleri Fakültesi, Sosyal Hizmet Bölümü, Aktaş Mahallesi \\ Plevne Caddesi No:5 PK: 06080 Altındağ / ANKARA
}

Özada A, Duyan V. Ebeveyn-Çocuk İlişkisi ve Zorbalık. TJFMPC, 2018;12(1): 49-55. DOI: 10.21763/tjfmpc.399941 


\section{GíRIŞ}

Zorbalık farklı disiplinlerden pek çok araştırmacının dikkatini çeken bir konudur. Literatür incelendiğinde 1980'ler sonrasında konu ile ilgili araştırmaların hızlı bir şekilde artış gösterdiği görülmektedir. Zorbalık, bir öğrenci ya da bir öğrenci grubu tarafından, başka bir öğrenciye fiziksel ya da psikolojik baskıda bulunma ve zamanla bunu standart bir yapıya kavuşturma olarak tanımlamaktadır. ${ }^{1}$ Akran zorbalığı; fiziksel, zihinsel ya da psikolojik olarak avantajlı bir öğrencinin herhangi bir mantıklı açıklaması olmaksızın daha zayıf olan bir öğrenciyi incitme isteği olarak açıklanmaktadır. ${ }^{2}$ Bir eylemin zorbalık olarak tanımlanabilmesi için; eylemin planlı olarak bir başka kişiye yöneltilmesi ve sonucunda bir zararın ortaya çıkması, eylemin tekrarlanması ve eylemi uygulayan ile zorba davranışın yöneltildiği taraflar arasında güç dengesizliğinin bulunması gerekmektedir. ${ }^{1}$

Akran zorbalığının yaygınlığı ile ilgili çalışmalar incelendiğinde genellikle zorbalığın $\% 5$ ile \%15 arasında değiştiği belirtilmektedir. ${ }^{3}$ Birleşmiş Milletler Çocuklara Yardım Fonunun (UNICEF) 18 farklı ülkede 100.000 gencin katılımıyla gerçekleştirdiği bir araştırmada katılımcıların üçte ikisinin zorbalık kurbanı oldukları belirlenmiştir. ${ }^{4}$ Zorbalık Türkiye için de yaygın bir sorundur. Lise öğrencileri üzerinde yapılan bir çalışmada öğrencilerin \%44'nün sözel, $\% 30$ 'unun fiziksel, \%18'inin duygusal ve \%9'unun cinsel zorbalığa maruz kaldığı saptanmıştır. ${ }^{5}$ Ayrıca zorba, mağdur ve zorba/mağdur rolünde zorbalığa karışan çocukların toplam oranı $\% 23$ olarak belirlenmiştir. ${ }^{6}$ Zorbaca davranışlar uygulama ve bunlara maruz kalmaya etki eden unsurlar değişkendir. Aile, okul, arkadaşlar, sosyodemografik özellikler, kişilik yapısı gibi birbirinden farklı pek çok etken zorbalığa neden olabilmektedir. Literatürde zorbaca eylemler uygulama ya da bu eylemlere maruz kalmada ailenin önemli bir faktör olduğu belirtilmektedir. ${ }^{7,8}$ Sosyalizasyon sürecinin en önemli parçası olarak kabul edilen anne-baba, çocukların bilişsel, duyuşsal ve sosyal gelişimlerini etkilemektedir. ${ }^{9}$ Kısaca, bir çocuğun anne-babasıyla erken yaşlarda kurduğu ilişki ve ilişkinin niteliği gelecekteki davranışlarının belirleyicisidir.

Ebeveyn-çocuk ilişkisinin en önemli üç bileşeni; bağlanma, sosyal destek ve aile sistemidir. ${ }^{10}$ Ebeveynlerin çocuğu disipline etme tarzları ile aile ortamı da çocuğun davranışları ile ilişskilendirilmektedir. ${ }^{11}$ Bağlanma ve erken dönemdeki ebeveyn çocuk ilişkisinin kalitesi ilerleyen yaşlardaki içe dönük ve dişa dönük davranış biçimlerini etkilemektedir. ${ }^{12}$ Zorbaca davranışlar uygulayan ergenlerin otoriter aile yapısına sahip oldukları, ebeveynlerin disiplin sağlamaya yönelik fiziksel cezalandırmaya başvurdukları ve sıklıkla tartışmaların yaşandığı destekleyici olmayan aile ortamlarında büyüdükleri belirtilmektedir. ${ }^{13}$ Ayrıca 4-6 yaş arası 104 çocuğun katılımıyla gerçekleştirilen bir araştırmada zorbaca davranışlar sergileyen çocukların ebeveynlerine güvensiz bağlandıkları ortaya konulmuştur. ${ }^{14}$ Benzer şekilde zorba eylemlerin kurbanı olanlarla ilgili boylamsal bir araştırmada çocukların güvensiz bağlanma yaşadıkları belirlenmiştir. ${ }^{10}$ Çeşitli araştırmalarda zorbalığın kurbanı olma ve ebeveynlere bağımlılık arasında da ilişki bulunmuştur. ${ }^{15}$ Özellikle ebeveynlerden birinin veya her ikisinin aşırı koruyuculuğu çocuğun zorbalık mağduru olma riskini artırmaktadır. Türkiye'de yapılan çeşitli çalışmalarda da ebeveyn tutumlarının zorbalığa etki ettiği tespit edilmiştir. Otoriter anababa tutumunun hâkim olduğu ailelerde yetişen çocuklarda saldırganlık oranının yüksek olduğu belirtilmektedir. Aynı çalışmada demokratik anababa tutumunun saldırganlık için koruyucu bir faktör olduğundan bahsedilmektedir. ${ }^{16}$ Zorbalık uygulayıp aynı zamanda zorbalığın kurbanı olan öğrenciler diğer gruplarla karşılaştırıldığında ebeveynleriyle çatışmalı ilişkilerinin olduğu ve daha düşük ebeveyn desteğine sahip oldukları belirtilmektedir. ${ }^{17}$ Bazı anne-babaların çocuklarını aşırı derecede şımartması, hiçbir zaman çocuklarının yanlış yapabileceğini kabullenmemesi zorbalığa yol açabilmekte ve ebeveynleri tarafından aşırı derecede şımartılan çocuklar kronik zorbalar olabilmektedir. ${ }^{18}$

Zorba davranışlar ve aile ilişkisi incelendiğinde, çocuğun anne-babasını algılayışının da saldırgan davranışlarla ilişkili olduğundan bahsedilmektedir. Konu ile ilgili bir çalışmada çocukların yaklaşık \%24'ünün ebeveynlerini katı veya çok katı gördükleri saptanmıştır. Çocukların ebeveynlerine yönelik bu tür algıları yetersizlik hissi, hayal kırıklığı yaşama, evde huzursuz olma ve evden kaçma gibi davranışlara neden olabilmektedir. ${ }^{19}$

Aileye ilişkin önemli faktörlerden biri de ailenin kalabalık olmasıdır. Kalabalık ailede az ilgi gördüğünü, ikinci planda kaldığını, kendisine karş1 ilgisiz davranıldığını, ailede kabul edilmediğini düşünen çocuğun, kendisini fark ettirmek için yanlış yollara başvurma girişiminin olabileceğinden bahsedilmektedir. Aile içinde kendini yalnız hisseden bir çocuğun, arkadaş grubunda çeşitli problemler yaşama, akran istismarı uygulama ya da maruz kalma gibi durumlarla karşılaşması olasıdır. ${ }^{20}$ Ailenin sosyo-ekonomik durumunun zorba ve zorba/kurban olma durumu üzerinde oldukça etkili olduğu belirtilmektedir. Bir ailedeki ebeveynin tek olması, birinin ya da ikisinin işsizliği, düşük eğitim seviyesi ve erken yaşta çocuk sahibi olmaları gibi durumlar, o ailedeki çocuğun zorba veya zorba/kurban olma riskini artırmaktadır. ${ }^{21} \mathrm{Bu}$ 
çalışmada aile ilişkisinin zorba, kurban ve zorba/kurban davranışları nasıl etkilediği ele alınarak, zorbalığı önlemeye ve azaltmaya yönelik uygulanabilecek üç farklı müdahale programından bahsedilmektedir.

\section{Ebeveyn-Çocuk İlişkisinin Zorbalığa Etkisi}

Ailenin en önemli görevi sosyalizasyon sürecinin bir parçası olan çocuğun bakım ve eğitim işlevinin gerçekleştirmesidir. Bu süreçte çocuk çeşitli davranış ve inanç normlarını öğrenerek bir kimlik oluşturmaktadır. Aile üyeleri bu sosyalleşme süreci içerisinde bir tür grup etkileşimine girerek çeşitli değerler, normlar ve inanışları yeni kuşağa aktarırlar. Kuşkusuz olumlu bir aktarımın söz konusu olabilmesi için aile üyelerinin iyi birer rol model olması, sağlıklı iletişim kurabilmeleri, katılımcı ve etkileşime açık olmaları önemlidir. Saldırgan davranış sergileyen çocukların ebeveynleri ile ilşkilerini araştıran bir araştırmada saldırgan davranışın nedenleri aile içinde sıcak-duygusal bir ilişki kurulamaması, çocuğun reddedilmesi veya aşırı derecede korunması olarak sıralanmaktadır.

Çocuğun uyumsuz ve saldırgan davranışlarına yönelik ailesel faktörler ele alınırken, bağlanma ve sosyal öğrenme kuramları üzerinde durulmaktadır. Bu kuramlar, zorbalığa ilişkin ailesel föktörleri ebeveyn tutumları, ebeveyn-çocuk ilişkisi ve ebeveyn-çocuk iletişimi odaklı ele almaktadır. ${ }^{22}$ Kimi yazarlar zorbalığın nedenlerine ilişkin ailesel faktörlere ailenin bulunduğu çevre ve ebeveynlerin katılımını da dahil etmektedir. ${ }^{23}$ Aile üyeleri arasında iletişimin kalitesi ebeveyn-çocuk ilişkisini güçlendirmekte ve çocuğun iyi olma durumuna katk1 sağlamaktadır. ${ }^{24}$ Ebeveyn-çocuk ilişkisinin çocuğun gelişimi ve ruhsal sağlığına etkisi incelendiğinde destekleyici ebeveyn-çocuk ilişkisinden yoksun olma durumunun pek çok sosyal, duygusal ve sağlığa ilişkin olumsuz durumlara yol açtığ belirtilmektedir. ${ }^{25}$ Açık ebeveyn-çocuk ilişkisi gençleri psikolojik ve davranışsal sorunlardan koruyan bir faktör olarak değerlendirilmektedir. ${ }^{26}$ Ebeveyn çocuk ilişkisi ele alınırken özellikle ergenlik dönemindeki bir gencin olumlu ebeveyn ilişskisine sahip olması riskli davranışlarda bulunmasını engelleyen koruyucu bir etmen olduğu unutulmamalıdır. ${ }^{27}$ Ailenin, bir çocuğun zorbaca davranışlarda bulunmasında, son derece önemli etkilerinin olduğu çeşitli yazarlar tarafindan literatürde belirtilmektedir. ${ }^{12,22}$ Hatta, zorba davranışlar uygulayan öğrencilerin, uygulamayanlara göre daha fazla aile içi sorunla başa çıkmaya çalıştıklarından bahsedilmektedir. ${ }^{27}$ Atik ve Güneri düşük kabul/katılım, yüksek otonomi ve düşük denetim şeklindeki ebeveyn tutumlarının zorba davranışların belirleyicisi olduğunu saptamışlardır. ${ }^{28}$ Çocuklar erken dönem ebeveynçocuk etkileşimine bağlı olarak duyuşsal ve bilişsel modeller oluşturmaktadırlar. ${ }^{29}$ Ergenlerin saldırgan davranışlarının incelendiği bir araştırmada ergenin yalnızca babaya ilişkin bağlılık duymasının saldırgan davranış sergileme olasılığını artırdığı saptanmıştır. ${ }^{29}$ Geleneksel zorbalık ile siber zorbalık eylemleri ebeveyn algısı bağlamında, 10-14 yaşları arasında $1.200 \quad$ ögrencinin katılımı ile gerçekleştirilen bir araştırmada incelenmiştir. Araştırmada siber zorbalık ile geleneksel zorbalık uygulayan ve maruz kalan kişilerin, zorbalık türü fark etmeksizin benzer özellikler gösterdiklerinden bahsedilmektedir. Hoşgörülü ailelerin çocuklarının zorbalık mağduru olma riskleri, ihmalkâr ailelerin çocuklarından daha düşüktür. ${ }^{30}$

Çocuk ve ergenlerin saldırgan tepkiler oluşturmasında dört ana etken ortaya konulmaktadır: 31

(a) Çocuğun bakımını üstlenen kişinin onun yaşamının ilk yıllarında yetersiz ilgi ve sevgiyle belirginleşen olumsuz bir tutum sergilemesi,

(b) Çocuğun bakımını üstlenen kişi ya da kişilerin çocuğun saldırgan davranışlarına izin verici tutumlar sergilemesi,

(c) Ailenin çocuğu yetiştirirken güç kullanması,

(d) Çocuğun mizacının aşırı hareketli olması ve sık öfke nöbetine tutulması.

Yukarıda belirtildiği gibi çocuğun bakımını sağlayan kişilerin çocuğun yetişkinlik döneminde sağlıklı bir kimlik oluşturmasında önemli sorumlulukları bulunmaktadır. Ebeveynlerin bireysel özellikleri, tutumları, ailenin sosyoekonomik durumu, aile ilişsileri, aile yapısı gibi çeşitli faktörler çocuğun gelecekte nasıl bir insan olacağını belirleyen unsurlardan birkaçıdır. Annebaba çocuğun saldırgan davranışlar sergilemesinde belirleyici olmanın yanında, saldırgan davranışların azaltılması ve önlenmesine ilişkin yapılacak çalışmalara doğrudan katılım göstermelidir. Aksi halde saldırgan davranışların azaltılması ya da önlenmesine yönelik başarı sağlanması mümkün değildir.

\section{Zorbalığı Önleme veya Azaltmaya Yönelik Müdahaleler}

Zorbalığı önlemeye yönelik müdahalelerde, zorbalığa karşı bir tutum geliştirilmesi, kurbanlara yönelik empatinin arttırılması, kurbanların başa çıkma becerilerinin yükseltilmesi, öğretmenlerin zorbalığa karşı tutum ve davranışlarının geliştirilmesi ve velilerin zorbalıkla ilgili farkındalıklarının arttırılarak zorbalık karşısında uygun tepkiler sergilemelerini sağlamaya yönelik eylemler hedeflenmelidir. Zorbaca davranışların görülmesine neden olan faktörler çeşitlidir. Zorba 
eylemler bireysel kaynaklı olabileceği gibi aile, okul, arkadaş, sosyo-demografik özellikler gibi pek çok nedenden kaynaklanabilir. Bu nedenle zorbalığ 1 azaltmaya ya da önlemeye yönelik müdahalelerde genellikle ekolojik yaklaşım kullanılmaktadır. ${ }^{9}$ Okul ortamlarında karşıllaşılabilecek zorbalık eylemlerinde bilişsel davranışçı yaklaşımların etkili olduğu, buna karşın destek sağlayıcı ya da sezgi yönelimli psikoterapi yaklaşımlarının genellikle etkili olmadığından bahsedilmektedir. ${ }^{1}$ Zorbalığ azaltmaya yönelik aile odaklı müdahaleler incelendiğinde aşağıdaki unsurların müdahalenin etkisini artırdığ 1 belirtilmektedir:

(a) Ebeveynlerin sıcak, empatik davranış modellemelerini arttırmak,

(b) Ebeveynleri düşmanca olmayan disiplin yöntemlerini kullanmaya teşvik etmek,

(c) Çocuğun faaliyetlerinin izlenmesi ve buna ilişkin katılımı artırmak..$^{32,33}$

"İyileştirici" tedavi de aile katılımının sağlandığ1 etkili okul müdahalelerinden sayılmaktadır ${ }^{23}$ Zorbalığın mağduru olan çocukların aileleriyle çalışırken, ebeveynlerin çocuklarına herhangi bir tehdit karşısında kendilerine güvenli ve yapıc1 olmaları konusunda aktif olarak yardım etmeleri beklenmektedir. Zorbalığın mağduru olan çocuklara yönelik programlarda, stres yönetimi, kendini sözel olarak savunabilme, akranlarından destek alma gibi becerilerin kazandırılması hedeflenmektedir. ${ }^{34}$ Zorbalığ ${ }_{1}$ önleme ve azaltmaya ilişkin programlarda okulda zorbalığın kabul edilemez bir durum olduğu mesajının verilmesi gerekmektedir. Sınıf içi aktivitelerde kuralların net olması ve düzenli bir şekilde tekrarlanması gerektiğine dikkat çekilmektedir. ${ }^{35}$ Zorbalıkla ilgili okul odaklı çalışılırken, öğrencilerle birlikte okul çalışanlarının da eğitilmesi gerektiği unutulmamalıdır. Okullarda zorba davranışlara ilişkin aşağıda sıralanan unsurları dikkate alan bir iklim oluşturulmasının, saldırgan davranışları azaltacağ belirtilmektedir. $^{36}$

(a) Mağdurlara hızlı bir şekilde yardım edilmesi,

(b) Zorbalı sonrasında net sonuçlar oluşturulması,

(c) Özellikle boş zamanlarda öğrencilerin daha yakından gözlemlenmesi,

(d) Öğrencilerin zorbalıkla nasıl baş edeceklerine dair eğitilmeleri,

(e) Okulda zorbalığa ilişkin politika ve uygulamalarla ilgilenen bir komitenin oluşturulması

\section{Olweus Zorbalığı Önleme Programı}

Olweus Zorbalığ1 Önleme Programı, okul personelini sıcak, 1lımlı ve katılıme bir okul ortamı yaratmaya yönlendirmektedir. Böylece onların birer yetişkin olarak, okuldaki onaylanmayan davranışları sinırlandırmada tutarlı olma ve kuralların çiğnenmesine düşmanca olmayan bir tavırla anında karşılık verme gibi özelliklerini geliştirerek hem disiplin sağlayıcı özelliklerini artırmakta hem de birer rol model olmaya teşvik etmektedir. Programda öncelikle zorbalığın yaygınlığını ve zorbaca davranışların türünü saptamak hedeflenmektedir. $\mathrm{Bu}$ tür davranışların genellikle okulun hangi bölgesinde işlendiği, zorba ve mağdur öğrencilerin zorbalığa ilişkin tutum ve inançlarının belirlenmesi, zorbalıkla ne ölçüde mücadele edildiği ve alınan önlemlerin ortaya çıkarılmasının önemi vurgulanmaktadır. Zorbalığa uygun tepki verilmediğinde zorba eylemlerin tekrarlaması olasıdır. Bu nedenle türü ne olursa olsun okulda zorbaca eylemlerin kabul edilemez olduğu vurgulanmalı, bu sorunla etkin bir biçimde baş edebilmek için uygun politikalar geliştirilmelidir. Ayrıca riskli grup olarak ifade edilebilen aile içi şiddete tanıklık eden, şiddete uğrayan, parçalanmış ailede yaşayan çocuklar belirlenmeli, zorbalık döngüsünün (zorba, mağdur ve izleyiciler) değişimi için çalışma grupları oluşturulmalı, zorbalığı önleme programlarına ailelerin katılımı sağlanmalıdır. Olweus Zorbalığı Önleme Programında öğrencilere insan hakları, sosyal beceriler, konuşma-atılganlık, dinleme, beden dili kullanma gibi olumlu iletişim becerileri geliştirme, problemleri şiddet kullanmadan çözme yaklaşımları öğretilmeli, öfke kontrolü, kendini ifade becerileri, benlik saygısını ve kendilik değerini artırmaya yönelik eğitimler, çatışma çözme, sosyal beceri eğitimleri verilmektedir. ${ }^{37}$

\section{Okulda Hayatta Kalma Programı}

Okulda hayatta kalma programı önleyici bir uygulamadır. Bu müdahalede okulda davranışsal zorluklar yaşamaya başlayan öğrenciler hedeflenmektedir. ${ }^{38}$ Okulda hayatta kalma programının amaçları sosyal hizmet değerleri ile uyumludur. Müdahalede verimsiz okul davranışının altında yatan çarpık sosyal algılardaki farkındalığ artırmak ve okul davranışına yönelik kişisel kontrol derecesi ile ilgili algıyı değiştirmek hedeflenmektedir. Bunlar, müracaatçının farkındalığının artırılması yoluyla güçlendirilmesi, kendi kaderini belirleme ve bilgilendirilmiş onamla uyumludur. ${ }^{39}$

Okulda hayatta kalma grubunun öncelikli hedefi katılımcıların okulda verimsiz davranışlara ilişkin sapmış sosyal algılarına yönelik bilinçli bir farkındalık yaratılmasıdır. Okulda hayatta kalma grubu okul davranışına yönelik kişisel kontrolün derecesine ilişkin öğrencilerin algılarını değiştirmeye odaklanan on oturumdan oluşan bir grup çalışmasından oluşur. Müdahalede grup üyelerine okul arkadaşları ve yetişkinlerle ilgili 
yaşanan çatışma durumlarına ilişkin pek çok yolun olduğu ve seçtikleri yolun hem olumlu hem de olumsuz bazı sonuçlarının olduğu aktarılmaktadır. Örneğin, bir grup üyesi, öğretmenin yönlendirmelerini dikkate alarak sınıfta olmaya devam edebilir ya da küfrederek disipline gönderilebilir. Ayrıca okul içinde düşük statü sahibi olan öğrenciler, öğretmenler ve okul yöneticileri ile güç yarışına girdiklerinde her zaman kaybedecekleri vurgulanmaktadır. Sonuç olarak, grup üyeleri "harekete geçmeden önce düşünün" şeklinde düşüncelerini geliştirmektedirler.

\section{İnanılmaz Yıllar: Ebeveyn Eğitim Programı}

Ebeveyn Eğitim Programı ebeveynlerin yetkinliklerinin güçlendirilmesi ve çocuğun okul deneyimine aile katılımının sağlanmasına odaklanmaktadır. Müdahalede çocukların akademik, sosyal, duygusal becerilerinin artırılması ve dikkat sorunlarının azaltılması amaçlanmaktadır. Program üç farklı gruba yönelik düzenlenmektedir. Birinci grup 0-12 ay arası bebeklere, ikinci grup 1-3 yaş arası çocuklara ve üçüncü grup 6-12 yaş arası okul çocuklarına yöneliktir. Program kapsamında ebeveynler 12-20 hafta arasında değișen, her biri 23 saat süren oturumlara katılmaktadır. Grup oturumlarında ebeveyn-çocuk etkileşimi, katı disiplini azaltma ve çocuğun sosyal, duygusal ve dil gelişimini ile ilgili ebeveyn becerisini artırmaya odaklanılmaktadır. ${ }^{40,41}$

\section{SONUÇ}

Zorba eylemlerin yaygınlığı ortaokul yıllarında en üst noktaya ulaşmaktadır. Bu açıdan, sağlıklı kimlik gelişimi için zorba eylemleri önlemeye ve azaltmaya yönelik etkili müdahalelere ihtiyaç duyulduğu açıktır. Ancak zorba eylemleri azaltmaya ve önlemeye yönelik herhangi bir müdahale programı uygulamaya başlamadan zorbalığın nedenlerinin anlaşılmasında yarar vardır. Zorbalığın nedenleri bireysel kökenli olabileceği gibi, ailesel ve çevresel de olabilmektedir. Gencin ailesi ve aile üyeleriyle etkileşimi zorba davranışı çeşitli yönlerden etkilemektedir. Aile içi şiddet ve buna tanıklık etme veya maruz kalma çocuğun saldırgan davranışı model almasına neden olmakta, karşılaştığı çeşitli olaylara saldırgan davranışla karşıllık verebilmektedir. Bunun yanında ebeveynlerin çocuğa sıcaklık göstermemesi, tek ebeveynli aile ve aile üyeleri arasındaki kopukluklar zorba davranış geliştirmeye ya da zorbalığa maruz kalmaya neden olmaktadır. ${ }^{42}$ Çocuğun kendini değerli hissettiği ve bir birey olarak kabul edildiği bir aile ortamında anne ve baba çocukla sevgi temeline dayalı sıcak bir ilişki kurar; aralarında eşitlikçi bir ilişki vardır, aile üyeleri birbirlerine sevgisini belli eder. Çocuğuna karşı sevgiden uzak bir ailede ise; çocuk küçümsenir, denetleme, cezalandırma, sinirli davranışlar, düşmanca tavırlar ön plandadır. Çocuk, reddedilir ve ana-baba ona karşı ilgisiz ve kayıtsızdır. Anne-baba çocuğunu kontrol ederken denetleyici ve kısıtlayıcı ise çocuğa karşı davranışlarında katıdır; onu her an denetleme arzusu duyar ve müdahale eder. Çocukla aşırı ilişki halinde olup onu kendine bağımlı kılmaya çalışır. Düzenli ve itaatkâr olması için baskı yapar, isteklerinin katı bir biçimde yerine getirilmesini ister ve çocuğu çevresinden soyutlar. Öte yandan serbestlik tanıyıcı ve hoşgörülü ana-babalar çocuğa özgürlük tanır. Çocuğunu aşırı biçimde denetlemez ve davranışlarına kısıtlama getirmez; zorlayıcı değildir. ${ }^{43}$ Zorba eylemleri azaltmaya ve önlemeye yönelik müdahalelerde yarar sağlanması adına ailenin katılımı sağlanmalıdır. Hem zorba eylemleri gerçekleştirenler hem de zorba eylemlerin mağduru olanlar açısından aile ilişkilerini de içeren çalışmaların barışçıl çözümler bulunmasına yarar sağlayacağı düşünülmektedir.

\section{KAYNAKLAR}

1. Dupper DR. Okul sosyal hizmeti. Özkan Y, Gökçearslan Çifci E, çev.editörleri.(trans. Eds.) 1. bask1. İstanbul: Kapital; 2013.p.34-35,40.

2. Pontzer DA. Theoretical test of bullying behavior: Parenting, personality, and the bully/victim relationship. Journal of Family Violence 2010;25(3):259-273.

3. Mishna F. Learning disabilities and bullying: double jeopardy. Journal of Learning Disabilities 2003; 36:1-15.

4. United Nations Educational, Scientific and Cultural Organization. School violence and bullying global status report. 2017: 9 .

5. Kepenekçi KY, Çınkır Ş. Öğrenciler arası zorbalık. Eğitim Yönetimi 2003;34:236-253.

6. Pekel UN, Uçanok Z. Akran zorbalı̆̆ gruplarında yalnızlık ve akademik başarı ile sosyometrik statüye göre zorba/kurban davranışı türleri. Türk Psikoloji Dergisi 2005;20(56):77-92.

7. Eşkisu M. The Relationship between bullying, family functions and perceived social support among high school students. Social and Behavioral Sciences 2014;159:492-496.

8. Akgün S. Akran zorbalığının anne-baba tutumları ve anne-baba ergen ilişkisi açısından değerlendirilmesi. Yayınlanmamış yüksek lisans tezi. Hacettepe Üniversitesi, Sosyal Bilimler Enstitüsü, 2005. p. 50-52.

9. Swearer SM, Espelage DL. A social-ecological framework of bullying among youth. Espelage DL ve Swearer SM, editor. Bullying in American schools: A social-ecological perspective on prevention and intervention London: Erlbaum; 2004. p.1-12.

10. Nickerson AB, Mele D, Osborne-Oliver KM. Parent-child relationships and bullying. In: Handbook of bullying in schools. Jimerson SR, 
Swearer, S M, Espelage DL, editor. ParentChild Relationships and Bullying. 1st ed. New York:Routledge; 2009. p.187-210.

11. Watt R. Attachment, parenting styles and bullying during pubertal years. Journal of Child Adolescent Health 2014;26(3):251-261.

12. Bosmans G, Braet C, Beyers W, Van Vlierberghe L, Van Leeuwen K. Power assertive discipline and internalizing problems in adolescents: The role of attachment. Parenting: Science and Practice 2014;11:34-55.

13. Yerger $\mathrm{W}$, Gehret $\mathrm{C}$. Understanding and dealing with bullying in schools. The Educational Forum 2011; 75(4): 315-326.

14. Monks CP, Smith PK, Swettenham J. Psychological correlates of peer victimisation in preschool: Social cognitive skills, executive function and attachment profiles. Aggressive Behaviour 2005;31:571-588.

15. Bowers L, Smith PK, Binney V. Perceived family relationships of bullies, victims and bully/victims in middle childhood. Journal of Social and Personal Relationships 1994;11:215232.

16. Eldeleklioğlu J. The relationships between aggressiveness, peer pressure and parental attitudes among Turkish high school students. Social Behaviour and Personality 2007;35(7):975-986.

17. Demaray MK, Malecki CK. Perceptions of the frequency and importance of social support by students classified as victims, bullies, and bully/victims in an urban middle school. School Psychology Review 2003; 32:471-489.

18. Elliott M. Bullies and victims. In: Elliott M, editor. Bullying. 3rd ed. UK: Pearson; 1997. p.1-11.

19. Glover D, Gough G, Johnson M, Cartwright N. Bullying in 25 secondary schools: Incidence, impact, and intervention. Educational Research 2000; 42:141-156.

20. Gültekin AG. A study on peer abuse among children at boarding and day schools. World Applied Sciences Journal 2010; 10(2):219-224.

21. Jansen P, Verlinden M, Berkel AD, Mieloo C, Ende J, Veenstra R, et al. Prevalence of bullying and victimization among children in early elementary school: do family and school neighbourhood socioeconomic status matter? BMC Public Health 2012; 12:494-504.

22. Lee SS, Wong DS. School, parents, and peer factors in relation to Hong Kong students' bullying. International Journal of Adolescence and Youth 2009; 15 (3):217-233.

23. Hilton JM, Anngela CL, Wakita J. A crosscultural comparison of factors associated with school bullying in Japan and the United States. The Family Journal 2010; 18 (4): 413-422.
24. Broberg M. Young children's well-being in Finnish stepfamilies. Early Child Development \& Care, 2012: 182: 401-415.

25. Clayton CL 'With my parents I can tell them anything': Intimacy levels within British Chinese families. International Journal of Adolescence and Youth 2014;19: 22-36.

26. Bireda AD, Pillay J. Perceived parent-child communication and well-being among Ethiopian adolescents. International Journal of Adolescence and Youth, 2017:1-9.

27. Davies SL, Crosby RA, Diclemente RJ: Family influences on adolescent health. In: DiClement RJ, Santelli JS, Crosby RA, editors. Adolescent Health: Understanding and Preventing Risk Behaviours. San Francisco: Jossey-Bass; 2009. p. 391.

28. Atik G, Güneri OY. Bullying and victimization: Predictive role of individual, parental, and academic factors. School Psychology International 2013; 34(6): 658-673.

29. Gallarin M, Alonso-Arbiol I. Parenting practices, parental attachment and aggressiveness in adolescence: A predictive model. Journal of Adolescence 2012; 35: 16011610.

30. Dehue1 F, Bolman C, Vollink T, Pouwelse M. Cyber bullying and traditional bullying in relation to adolescents' perception of parenting. Journal of Cyber Therapy \& Rehabilitation 2012; 5 (1): 125-134.

31. Güvenir T. Okulda akran istismarı. Kök Yayıncılık, Ankara; 2008.

32. Dishion TJ, Patterson G. Age effects in parent training outcome. Behaviour Therapy 1992; 23:719-729.

33. Kazdin AE. Treatment of antisocial behaviour in children: Current status and future directions. Psychological Bulletin 1987;102:187-203.

34. Sharp S. Self-esteem, response style and victimization: Possible ways of preventing victimization through parenting and school based training programmes. School Psychology International 1996; 17:347-357.

35. Olweus D, Limber SP, Mihalic S. The Bullying Prevention Program: Blueprints for Violence Prevention. Boulder, CO: Centre for the Study and Prevention of Violence; 1999. p.3.

36. Yerger $\mathrm{W}$, Gehret C. Understanding and dealing with bullying in schools. Educational Forum 2011;75:315-326.

37. Astor RA, Rosemond M, Pitner RO, Marachi R, Benbenishty R, Interpersonal conflict, violence, and classroom management best practices and resources, Franklin C, Harris MB, Allen-Meares P, editor. The School Services Sourcebook: A Guide for School-Based Professionals. 1st Ed. New York: Oxford University Press; 2006. p.423-441. 
38. Dupper D. An alternative to suspension for middle school youths with behaviour problems: findings from a "school survival" group. Research on Social Work Practice 1998;8(3):354-366.

39. Short RJ, Short PM. An organizational perspective on student discipline. Education 1994; 114:567-569.

40. Brower AM. ve Nurius PS. Social Cognition and Individual Change: Current Theory and Counselling Guidelines. $1^{\text {st }}$ ed. UK: SAGE; 1993. p.167.
41. Incredible Years Parent, Teacher, and Child Programs.

http://www.incredibleyears.com/programs/pare nt/ Erişim tarihi: 15.05.2017.

42. Flouri E, Buchanan A. The role of mother involvement and father involvement in adolescent bullying behaviour. J Interpers Violence 2003;18:634-44.

43. Schaffer ES. A circumflex model for maternal behaviour. Journal of Abnormal Social Psychology 1959;59:226-235. 